\title{
Despolitización de la función pública: análisis de eficacia del Sistema de Alta Dirección Pública en la República de Chile
}

\author{
William Rebollo \\ Universidad de Chile
}

\section{Resumen}

El presente estudio de caso analiza la experiencia de Chile para verificar la eficacia de la implementación de su Sistema de Alta Dirección Pública (SADP) como instrumento para disminuir el grado de politización de la función pública. El análisis se desarrolló con un enfoque exploratorio. Se ha podido constatar que efectivamente el SADP en Chile ha conseguido compatibilizar la profesionalización de los sectores fundamentales de la burocracia con el aumento de la responsabilización de los funcionarios públicos ante la sociedad y el sistema político, logrando con ello disminuir la politización de la función pública. Sin embargo, el análisis revela ciertas debilidades que podrían afectar la concreción de su propuesta de valor público, que requieren atención. Entre ellas se pueden mencionar: restricciones en la aplicación del subsistema de gestión del cambio organizacional debido a la rigidez del marco normativo; persistencia de algunos rasgos clientelares en el subsistema de gestión del desempeño, que tienen su raíz en el path dependence; y limitantes en el subsistema de gestión del desarrollo para incentivar el rendimiento y desarrollo profesional, especialmente en el ámbito de las remuneraciones.

Palabras clave: Sistema de Alta Dirección Pública, política, valor público.

Depolitization of the public function: analysis of the effectiveness of the High Public Management System in the Republic of Chile

\begin{abstract}
This paper analyze the experience of Chile to verify the effectiveness of the implementation of its Public Management System (SADP) as an instrument to decrease the degree of politicization of the civil service. The analysis was developed with an exploratory approach. It has been shown that indeed the SADP in Chile has reached to combine the professionalism of the key sectors of the bureaucracy with the increased accountability of public workers to society and the political system, thereby achieving to decrease the politicization of the civil service. However, the analysis reveals certain weaknesses that could affect the realization of its proposed public value that require attention. Weaknesses such as: restrictions on the application of the organizational change management subsystem because of the rigidity of the regulatory framework; persistence of some clientelism features in performance management subsystem, which are rooted in the path dependence; and limits in the development management subsystem to encourage the performance and professional development, especially in the field of remuneration.
\end{abstract}

Keywords: Public management, politics, public value.

*Dirección de correspondencia [Correspondence

address]: William Rebollo, Universidad de Chile

E-mail: willraf01@hotmail.com 


\section{Introducción}

En América Latina el clientelismo se presenta como una práctica común (Nickson, 2002), con una cultura política de favores, con sistemas de reclutamiento y promoción basados en un sistema de patronazgo más que de mérito. Sin embargo, según los resultados de un trabajo realizado en el contexto del Diálogo Regional de Política sobre Transparencia y Gestión Pública del Banco Interamericano de Desarrollo, se destacan algunos países o algunos enclaves de racionalidad y eficacia (Echebarría y Cortázar, 2007).

Dicho estudio evalúa la calidad de la administración pública de 18 países de América Latina bajo un marco común, destacando que en cuanto al grado de autonomía de la burocracia (medido mediante un índice de mérito), Brasil, Chile y Costa Rica lideran el grupo, reflejando una ejecución generalizada de los principios de mérito en las decisiones de selección, promoción y desvinculación de los funcionarios públicos (Echebarría y Cortázar, 2007). Para poder desempeñar papeles sustantivos en el diseño e implantación de las políticas públicas, además de autonomía, la administración requiere capacidades técnicas adecuadas e incentivos para un desempeño efectivo (lo cual se mide a través del índice de capacidad funcional). Así, el estudio revela que Brasil y Chile, lideran la región con una capacidad técnica considerable. Por otra parte, el estudio señala que en cuanto al grado en que las administraciones públicas responden a los mandatos y prioridades de los gobiernos (el cual se mide mediante un índice de consistencia estratégica), nuevamente las administraciones de Brasil y Chile son las que muestran resultados sobresalientes (Echebarría y Cortázar, 2007).

Pese a estos avances en Brasil y Chile, la gestión basada en méritos sigue siendo el gran reto de la reforma de la administración pública en América Latina. No obstante, no debe confundirse a los sistemas basados en méritos con la creación de una casta de funcionarios que, una vez han demostrado su competencia técnica, puedan evadir exigencias de rendimiento y responsabilidad. Tampoco debe hacerse con la creación de burocracias paralelas de "equipos técnicos o de proyectos" al amparo de los préstamos de organismos internacionales (Echebarría y Cortázar, 2007). Es importante por tanto, indagar sobre herramientas de mejora de la gestión pública que posibiliten al Estado disminuir las prácticas clientelares y la politización de su institucionalidad, de forma que le sea posible incrementar su capacidad de respuesta a las necesidades de la población a través de un servicio público centrado en los ciudadanos, que los reconozca como porta- dores de derechos y obligaciones, y por tanto participes y corresponsables de las políticas públicas (Aguilar, 2006).

El proceso de Chile, a diferencia del de Brasil que perdió potencia con la desactivación del ministerio especialmente creado para promoverlas (Ministerio de Administración y Reforma del Estado, MARE), se caracteriza por haber ganado impulso y alcance con el tiempo. En un primer momento (1990-94), la reforma de la administración no era una prioridad explícita en la agenda gubernamental, pero se desarrollaron iniciativas específicas para la nivelación de las condiciones en la administración y la modernización de la gestión de algunos organismos. Fue entre 1994 y 1996 que el tema ganó peso dentro de la agenda del gobierno, generándose un conjunto de iniciativas orientadas a cambiar el centro de atención de la administración pública hacia la eficiencia, la eficacia y la calidad del servicio. Se creó, además, un Comité Interministerial responsable de supervisar el proceso de reforma, al interior del cual adquirió un liderazgo central el Ministerio de Hacienda (Rehren, 2000; Echebarría y Cortázar, 2007; Tello Navarro, 2011). A partir de 1997 se ejecutó un programa ya estructurado de reforma en varias dimensiones de la administración, con una definición estratégica e iniciativas de carácter más integral en áreas como tecnologías de información, compras gubernamentales, rediseño gerencial y gestión por resultados. Con ello, entre otros aspectos, se logró establecer un sistema de convenios de gestión y un sistema de evaluación por resultados, ambos vinculados a la asignación presupuestal de cada organismo. Finalmente, en 2003 se puso en práctica una significativa reforma del empleo público, como parte de los Acuerdos Políticos-Legislativos para la Modernización del Estado, instaurándose el Sistema de Alta Dirección Pública que permite la selección de los altos directivos con base en sus méritos, así como una nueva política en materia de acceso a cargos y carrera del personal profesional (Armijo, 2002 citada en Echebarría y Cortázar, 2007: 147; Echebarría y Cortázar, 2007; Tello Navarro, 2011).

La implementación del Sistema de Alta Dirección Pública como sistema de gestión de recursos humanos de la gerencia pública, ha logrado desarrollar un nivel directivo independiente del conjunto de la carrera funcionaria, y distinto del nivel de confianza política, obteniendo así un adecuado equilibrio entre los criterios técnicos y políticos en la conformación de su gerencia pública (Cortázar, 2011), lo cual es de vital importancia para la creación del valor público que demanda la población por parte de las instituciones (Moore, 1998). Esta situación puede impulsar procesos de aprendizaje organizacional en relación a la reforma del Estado (Levitt y March, 1988). 
Es por ello que el presente estudio de caso tiene como objetivo analizar la eficacia del Sistema de Alta Dirección Pública en la República de Chile como instrumento para disminuir la politización de la función pública, de forma que sirva de insumo para futuras investigaciones que pretendan profundizar sobre el tema.

\section{Función pública y valor público}

El valor de las instituciones públicas, debe ser concretizado a partir de la labor realizada por los servidores públicos quienes se articulan mediante la función pública como agentes fundamentales de la administración estatal. Por tal motivo, existe actualmente en América Latina un consenso respecto a la importancia que tiene la calidad de los sistemas de función pública al momento de elevar la calidad de la acción estatal, y sobre la necesidad de reforma de esos sistemas. Considerar a los directores públicos en una reforma de la función pública se vuelve entonces clave, pues estos constituyen la interface entre el ejecutivo político y la administración pública, y son los responsables de la implementación apropiada de instrumentos legales, estrategias y medidas políticas, y de la consistencia, eficiencia $\mathrm{y}$ adecuación de la actividad gubernamental.

Longo (2002b) presenta un modelo teórico de referencia en su dimensión más global, precisando la razón de ser de la gestión de recursos humanos, su valor estratégico y los factores situacionales que en todo caso deben ser considerados. La gestión de recursos humanos es presentada en este modelo como un sistema integrado de gestión, cuya finalidad básica es la adecuación de las personas a la estrategia de una organización o sistema multiorganizativo, para la producción de resultados acordes con las finalidades perseguidas. La coherencia estratégica es un rasgo fundamental del modelo, pues la gestión de recursos humanos no crea valor sino en la medida en que resulta coherente con las prioridades y finalidades organizativas (Longo, 2002a).

En el nivel superior, la Planificación de Recursos Humanos, constituye la puerta de entrada al sistema integrado de gestión de recursos humanos, permitiendo anticipar la definición de políticas coherentes en todos los restantes subsistemas, con los que aparece conectada (Longo, 2002a). En el nivel intermedio, hay cinco subsistemas, ordenados en horizontal en cuatro bloques, con arreglo a una secuencia lógica: en el primero, la Organización del Trabajo, que prefigura y concreta los contenidos de las tareas y las características de las personas llamadas a desempeñarlas. En el segundo, la Gestión del Empleo, que comprende los flujos de entrada, mo- vimiento y salida de las personas. En el tercero, la Gestión del Rendimiento, que planifica, estimula y evalúa la contribución de las personas. En el cuarto, por una parte, la Gestión de la Compensación, que retribuye la contribución; y finalmente, la Gestión del Desarrollo, que se cuida del crecimiento individual y colectivo. Por último, en el nivel inferior, la Gestión de las Relaciones Humanas y Sociales, que se relaciona a su vez con todos los subsistemas mencionados anteriormente (Longo, 2002a).

Se puede definir el valor público como aquel valor agregado que produce el sector público, desde el punto de vista de los beneficios percibidos por la comunidad, así como por los usuarios directos o consumidores de los servicios o prestaciones públicas (Díaz, 2011). Debe señalarse entonces, que en el proceso político-administrativo, las percepciones sociales sobre la manera en que responde a las distintas demandas aumentan o disminuyen el valor creado (Echebarría y Mendoza, 1999). El organismo debe captar las preferencias de los ciudadanos, pero también aprender de ellos, de sus opiniones, intereses, experiencia y conocimiento colectivo, pues son ellos quienes determinan y autorizan lo que es valioso.

Ahora bien, una vez identificado el valor público que desea la población, es necesario además para la organización determinar una serie de estrategias que le permitan la consecución de ese valor. Para ello debe entonces establecerse un conjunto de suposiciones acerca de cómo se desempeñará para la creación de ese valor. La organización entonces debe definir un modelo de negocio que indique cómo se estructurará y operará para la producción del valor público (Magretta y Stone, 2003) y cómo lo llevará a sus clientes, usuarios y stakeholders de carácter público y estratégico (Waissbluth y Larraín, 2009).

\section{Director Público y Alta Dirección Pública}

Los directores públicos son verdaderos estrategas en la gestión pública. Miran hacia afuera intentando averiguar el valor de lo que están haciendo, y también hacia abajo, intentando determinar la eficacia y la adecuación de sus medios. Involucran a los políticos que rodean a su organización para ayudarles a definir el valor público y a diseñar la gestión de sus organizaciones, y anticipan un mundo de conflictos políticos y tecnologías cambiantes que con frecuencia les obliga a rediseñar sus organizaciones en lugar de esperar un entorno estable que les permita perfeccionar sus operaciones actuales (Moore, 1998). Deben generar valor público integrando una reflexión sustantiva sobre lo que es valioso y eficaz, 
un diagnóstico de las expectativas políticas, y un análisis detallado de lo que es viable operativamente, integrando de esa forma la dimensión política, la dimensión sustantiva y la dimensión administrativa, todas ellas necesarias para la creación de ese valor público (Moore, 1998).

Henri Fayol (1949 citado en Corcuera, 2001: 27), establece cinco funciones del trabajo directivo: previsión, organización, mando, coordinación y control. Su labor requiere de alta cantidad y ritmo de trabajo, y sus actividades se caracterizan principalmente por su brevedad, variedad y fragmentación (Mintzberg, 1983 citado en Losada, 1999: 399). Esa variedad de actividades que se presentan para el director en las organizaciones públicas, implican desempeñar cuatro roles fundamentales: toma de decisiones, gestión de la información, gestión de relaciones interpersonales y conceptualización (Losada, 1999).

Para que el director pueda desarrollar sus funciones en el sector público, es necesario que se le dote con un nivel discrecional que le permita ejercer las funciones directivas, al mismo tiempo que se institucionalicen mecanismos de responsabilidad por la función pública. Se requiere además de un régimen administrativo específico en el cual se establezcan obligaciones, sanciones, y recompensas (Catalá, 2005) para de esa forma propiciar en mayor medida la producción del valor público en las instituciones públicas.

La acción pública ha estado repartida durante décadas entre dos grandes protagonistas: una clase política, investida de autoridad a través de los mecanismos de la democracia representativa; y una función pública profesional, regida por el sistema de mérito (Longo, 2002b). La aparición de los directores y de los sistemas de alta dirección pública supone la ruptura de ese dualismo, no solo en el funcionamiento de las administraciones, sino en la propia conciencia social (Longo, 2002b), por lo que comienzan a ser vistos como una de las piezas fundamentales de la reforma de la función pública (Ramos et al., 2011). Estos sistemas responden a dos desafíos: primero, contar con una gerencia pública que tenga habilidades y competencias específicas; y segundo, responder al desafío de vencer la falta de continuidad y fragmentación, para brindar más estabilidad a la gerencia pública (Lafuente, 2011). Sin embargo, la experiencia nos muestra que cada administración pública configura su sistema de alta dirección pública de acuerdo a sus propias realidades y necesidades (Lafuente, 2011).

\section{Profesionalización vs Politización de la función pública}

La mayor parte de las relaciones y acciones de la administración pública implican el ejercicio del poder, y por eso no es de extrañar que se confundan en la práctica las instituciones políticas y administrativas, así como también se confunden sus integrantes, especialmente en el vértice superior de las organizaciones, generando relaciones de dominación en las que el ciudadano se ve sometido a las instituciones políticas y administrativas y a sus integrantes (Arenilla, 2010).

Desde la perspectiva del CLAD; el aplanamiento de las estructuras organizacionales, la reducción del personal público, la búsqueda de la eficiencia en todas sus dimensiones y la extrapolación del modelo de administración privada a la administración pública; no resuelven en su totalidad los problemas generados en el tercer mundo, sino que son necesarios además mayores niveles de democracia, tanto al interior de la administración pública como en la sociedad, pues la administración cumple un papel fundamental al tratar de unir los objetivos del gobierno con las necesidades de la sociedad (Araya y Cerpa, 2008).

De esa forma, los planteamientos del CLAD no conciben el desmantelamiento del aparato gubernamental ni de la burocracia, sino por el contrario, proponen una nueva burocracia profesional, bien remunerada y meritocrática, con un rol central de los directores públicos, en donde las funciones accesorias sean llevadas a cabo por servicios externalizados y que la acción ejecutiva del gobierno se lleve a cabo con transparencia en base a los principios de la democracia y del control ciudadano (Araya y Cerpa, 2008).

Por ello la discusión profesionalización/politización de la función pública toma nuevamente un rol central en las diferentes propuestas de reforma del Estado. América Latina ha estado buscando la despolitización del servicio público mientras numerosos países de la OCDE han estado considerando la re-politización del mérito, como forma aumentar su capacidad de respuesta y su desempeño (Manning et al., 2009). Pareciera que un balance entre ambos procesos podría ser la respuesta a los problemas de gestión que presenta actualmente la administración pública. Por ello es necesario que los directivos piensen estratégicamente para que asignen igual importancia a la definición sustantiva del valor que creará la intervención, la gestión operativa y la política, y realizar una integración de las tres perspectivas, generándose así las condiciones 
necesarias para la creación de valor público. Esta concepción integral con funciones operativas y políticas sobre la función directiva pública eleva entonces el rol del director público, pasando de sólo seleccionar métodos administrativos efectivos para implementar el mandato político o legal (identificado como un rol puramente técnico), a analizar el entorno político y operativo de su organización para detectar oportunidades con el fin de generar valor público (lo que constituye más el rol de un estratega) (Trefogli, 2013).

La institucionalización de la función pública en su forma moderna de sistema de mérito (Prats, 1999), se ha caracterizado por estar basada en un conjunto de valores, principios y normas que integran el sistema de mérito y que se han institucionalizado porque resuelven problemas inherentes a la ordenación de la acción colectiva (Prats, 1999). Los funcionarios se reclutan entonces a partir de mecanismos abiertos, y se privilegian sus credenciales y méritos, y estos ejercen sus tareas en el marco de carreras profesionales estructuradas, con buenas oportunidades de movilidad y aprendizaje. Se combina de esta manera una alta autonomía con una alta capacidad técnica (Iacoviello y Essayag, 2011), logrando una profesionalización de la función pública (Oszlack, 2002).

Una función pública profesional, sujeta a reclutamiento por sus competencias, por vías transparentes y competitivas, aleja los riesgos de la partidización que, con recurrencia, obstruyen la configuración del tipo de políticas que sostienen la trayectoria del progreso más allá de cada turno de gobierno. Se fortalece la confianza de los actores al tiempo que evita la captura de las políticas públicas por parte de intereses corporativos (Iacoviello, Pando, Mendelson \& Essayag, 2010 citado en Iacoviello y Essayag, 2011: 2).

Sin embargo, este tipo de burocracias presentan el riesgo de causar el "síndrome del técnico", en el cual los directores públicos hacen buena definición de la política pública, poseen una buena capacidad de gestión pero una incapacidad de gestión del entorno, produciendo que el resultado de la gestión del director público en relación a la producción de valor público genere un impacto final muy reducido (Losada, 1999).

También existen burocracias clientelistas, basadas en un sistema de patronazgo ${ }^{1}$ que data de tiempos históricos y que sigue vigente de diversas formas en muchos países de la región como forma de responder a intereses del poder político (Prats, 1999).

\footnotetext{
${ }^{1} \mathrm{Se}$ entiende por patronazgo, la tendencia del poder político a administrar los cargos y empleos públicos como un botín electoral (Prats, 1999).
}

El clientelismo se configura entonces en estas sociedades como una "dependencia personal no ligada al parentesco, que descansa en un intercambio recíproco ${ }^{2}$ de favores entre dos personas, el patrón y el cliente, quienes controlan recursos desiguales" (Médard, 1976 citado en Barozet, 2006: 79).

El fenómeno del clientelismo impacta de manera directa en la burocracia estatal, pues tiende a copar el empleo público, posibilitando que no se exija a los funcionarios un determinado nivel de formación o experiencia, pues el empleo sirve de recompensa a cambio del voto, por lo que la profesionalización del empleo público tiende entonces a mantenerse baja en los estados clientelares, lo que redunda en reducidos niveles de eficiencia pública y una inevitable captura del Estado y de sus agencias de parte de determinados sectores políticos (Barozet, 2006) y, a la postre, en corrupción y deslegitimación del sistema político-administrativo (Prats, 1999).

Se caracterizan además por una baja autonomía, por baja capacidad de gestión, por contar con funcionarios que ingresan temporalmente al gobierno según criterios de confianza o afiliación partidaria, y por ser utilizadas como recurso político del partido gobernante para obtener votos o apoyos políticos (Echebarría y Cortázar, 2007) pues bajo éste sistema los partidos políticos pueden basar su éxito electoral en su capacidad para ofrecer empleos estatales o ventajas para sus militantes y/o simpatizantes $^{3}$ (Rehren, 2000).

Las burocracias clientelares funcionan entonces como una extensión más del actor político partidario, y pueden tener alguna capacidad de veto frente a segmentos burocráticos profesionales o basados en méritos, con los que pueden entrar en conflicto (Echebarría y Cortázar, 2007) o pueden también adaptarse a los cambios y subsistir en formas más diversificadas $^{4}$ (Barozet, 2006). Estas burocracias

\footnotetext{
${ }^{2}$ Según Freidenberg (2015) las prácticas clientelares están generadas por la noción de reciprocidad, la cual responde a una norma universal basada en dos premisas: que la gente ayudará a los que le ayudaron con anticipación y que no les provocará ningún daño. Los integrantes del intercambio comparten una regla moral, que supone que se deben cosas mutuamente y que les obliga a unos y otros a desarrollar el intercambio.

${ }^{3}$ En las democracias emergentes que requieren de la selección de líderes a través del sufragio universal y competencia entre partidos, el clientelismo político ha tenido su más fiel expresión en los "partidos de máquina", los cuales, más que actuar en base a principios políticos son una organización no-ideológica interesada en asegurar puestos y en distribuir ingresos para sus líderes y quienes trabajan para ellos (Scott, 1969 citado en Rehren, 2000, p.131).

${ }^{4} \mathrm{El}$ clientelismo se ha adaptado a la mayor transparencia de la vida política, a su mayor competitividad y asimismo a la mayor politización de los electores, por ello, el clientelismo debe verse como un tema más complejo, no solamente como una reacción pasiva de los electores más necesitados, sino como un cálculo razonado e incluso estratégico frente a lo que
} 
pueden constituirse en un obstáculo para la modernización y reforma del Estado (Barozet, 2006) pues incrementan el riesgo del síndrome del "yo soy político, la gestión no es cosa mía" en el cual el director público posee una definición deficiente de la política pública, baja capacidad de gestión, pero buena capacidad de gestión del entorno, generando un impacto final muy reducido en relación a la creación del valor público (Losada, 1999).

\section{Metodología}

Se llevó a cabo un diagnóstico institucional de los subsistemas de gestión de recursos humanos aplicados a los cargos adscritos al mismo, desarrollada a partir de un enfoque de tipo exploratorio bajo el modelo de análisis del institucionalismo histórico (path dependence), abordando la implementación del Sistema de Alta Dirección Pública dentro de su contexto político-social y como parte de un proceso de reforma y modernización del Estado.

Se utilizaron herramientas tanto de análisis cualitativo como cuantitativo para la investigación: inspección de registros y documentos, revisión de prensa, análisis documental, entrevistas exploratorias, indicadores, y estadística descriptiva. Se analizó la eficacia funcional, utilizando técnicas de recopilación de datos y dos entrevistas exploratorias con actores directamente involucrados en la aplicación del Sistema de Alta Dirección Pública, habiéndose realizado la primera en el mes de junio y la segunda en el mes de agosto de 2014.

Se identificaron el modelo de negocio, utilizando el método Canvas (Osterwalder y Pigneur, 2009), y la cadena de valor (Porter, 1987) del Sistema de Alta Dirección Pública. Posteriormente, se realizó un diagnóstico de los subsistemas de gestión de recursos humanos del Sistema de Alta Dirección Pública aplicados a los cargos adscritos al mismo para la concreción de su propuesta de valor público (subsistema de gestión del desempeño y subsistema de gestión del desarrollo), para verificar si efectivamente contribuye a disminuir la politización de la función pública. Para ello, se elaboraron una serie de indicadores para medir el mérito y capacidad funcional promovidos por el SADP en la gerencia pública, utilizando como referencia el Marco Analítico para el Diagnóstico Institucional de Sistemas de Servicio Civil (Longo, 2002a), establecido por el Banco Interamericano de Desarrollo como resultado de una sistematización del conocimiento, y el Manual de Indicadores de Desempeño en el Sector Público (Bonnefoy y Armijo, 2005), formulado por la Comi-

pueden ofrecer los políticos en tiempo de campaña electoral. sión Económica para América Latina y el Caribe. Se aplicaron en una línea de tiempo comprendida desde período del año 2004, correspondiente a la implementación del Sistema, hasta el período del año 2014 (fecha de corte: 26-09-2014), para constatar, por medio del análisis estadístico, las líneas de tendencia y los cambios generados por la implementación del Sistema de Alta Dirección Pública.

\section{Modelo de negocio y cadena de valor del Sistema de Alta Direc- ción Pública}

\section{Modelo de Negocio del Sistema de Al- ta Dirección Pública}

El método Canvas (Osterwalder y Pigneur, 2009) es una herramienta que facilita comprender el modelo de negocio de una organización a partir de nueve módulos básicos que muestran la lógica de cómo una organización pretende crear valor. Los nueve módulos cubren las cuatro áreas principales de un negocio: oferta, clientes, infraestructura y viabilidad financiera. Esto brinda una imagen para poder implementar una estrategia a través de los procesos, sistemas y estructuras organizacionales; se clarifican los canales de distribución y las relaciones entre las partes, se determinan los beneficios e ingresos y especifican los recursos y actividades esenciales que determinan los costos más importantes, y se pueden determinar además las alianzas necesarias para operar.

Los nueve bloques básicos del método son (Osterwalder y Pigneur, 2009):

- Propuestas de valor: describe la variedad de productos y servicios que crean valor para un segmento de clientes específico. El objetivo es de definir el valor creado para cada segmento de clientes describiendo los productos y servicios que se ofrecen a cada uno.

- Segmentos de clientes: define los diferentes grupos de personas, organizaciones y empresas que se quieren alcanzar y atender. El objetivo es de agrupar a los clientes con características homogéneas en segmentos definidos y describir sus necesidades, averiguar información geográfica y demográfica, gustos, etc. Después, uno se puede ocupar de ubicar a los clientes actuales en los diferentes segmentos para finalmente tener alguna estadística y crecimiento potencial de cada grupo. 
- Relación con el cliente: son los tipos de relaciones que la compañía establece con los segmentos específicos de clientes. Aquí se identifican cuáles recursos de tiempo y monetarios se utiliza para mantenerse en contacto con los clientes.

- Canales: se refiere a la manera en que se establece contacto con los clientes para entregarles la propuesta de valor. Para cada producto o servicio identificado hay que definir el canal de su distribución adecuado.

- Actividades clave: se utiliza para saber qué es lo más importante a realizar por la organización para que el modelo de negocios funcione. Utilizando la propuesta de valor más importante, los canales de distribución y las relaciones con los clientes, se definen las actividades necesarias para entregar la oferta.

- Recursos clave: se refiere a los insumos más importantes que se requieren para que el modelo de negocio funcione. Saber cuáles son los recursos clave que intervienen en la generación de valor permite que la organización tenga la capacidad de entregar su oferta o propuesta de valor.

- Alianzas estratégicas: hace relación a la red de proveedores y de socios, ya sean públicos o privados, que hacen posible que el modelo de negocio funcione.

- Fuentes de ingresos: representa el recurso monetario que una organización genera por cada segmento de cliente y la forma en que estos ingresos se obtienen.

- Estructura de costos: presenta todos los costos incurridos por la organización para operar el modelo de negocio. Se especifican los costos de la empresa empezando con el más alto y luego se relaciona cada costo con los demás módulos.

Aplicando entonces el método Canvas (Osterwalder y Pigneur, 2009) al SADP, se obtiene lo siguiente:

- Propuestas de valor: el Modelo de Negocio del SADP parte de la idea de la existencia de una propuesta de valor público, la cual consiste en dotar a las instituciones del gobierno central de equipos directivos altamente calificados para desempeñarse en la gestión pública, de forma que optimicen la entrega de bienes y servicios a la ciudadanía y den cumplimiento a las políticas y programas definidos por la autoridad (DNSC, 2013a; Consejo de Alta Dirección P $\tilde{A}^{o}$ blica, 2013).
- Segmentos de clientes: la segmentación de clientes parte de su propuesta de valor público, y al ser las destinatarias de ella las instituciones del gobierno central, los clientes son: El Presidente de la República, los Ministros y Jefes de Servicio (DNSC, 2013a; Consejo de Alta Dirección P $\tilde{A}^{0}$ blica, 2013).

- Relación con el cliente: La propuesta de valor implica una relación con los clientes de forma personalizada, la cual tiene como punto de partida la solicitud de provisión del cargo realizada por el respectivo Ministro al Consejo de Alta Dirección Pública y por la construcción del perfil de selección (Consejo de Alta Dirección P $\tilde{A}^{\underline{o}}$ blica, 2013).

- Canales: los canales de distribución del modelo de negocio corresponden a unidades institucionales que entregan la propuesta de valor a los clientes. Así durante el proceso de reclutamiento y selección, los canales del SADP son el Concejo de Alta Dirección Pública, en lo que corresponde al I Nivel Jerárquico, y el Comité de Selección, en cuanto al II Nivel Jerárquico, los cuales, a través de diferentes oficios concluyen con la presentación de la nómina de candidatos elegibles a la autoridad (Presidente de la República para el I Nivel Jerárquico, y Jefe de servicio para el II Nivel Jerárquico) (Consejo de Alta Dirección P $\tilde{A}^{o}$ blica, 2013).

Otro canal importante durante todo el ciclo de vida laboral del directivo público lo constituye la DNSC quien realiza un rol fundamental a través de sus diferentes unidades, entre las cuales cabe destacar la Subdirección de Alta Dirección Pública, cuyas principales funciones son coordinar y administrar los procesos concursales, informar los avances de los concursos al CADP, elaborar perfiles de selección y descripciones de cargos, actuar como contraparte técnica de las empresas consultoras a cargo de la búsqueda y evaluación de Altos Directivos Públicos, coordinar acciones con ministerios y servicios públicos para el adecuado desarrollo de los concursos a su cargo y, en general, realizar las acciones necesarias para asegurar el eficiente y eficaz funcionamiento del SADP (Consejo de Alta Dirección

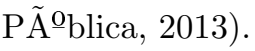

La Subdirección de Alta Dirección Pública, se estructura en cuatro áreas: Reclutamiento y Selección, Educación, Calidad y Remuneraciones, a las que se suma el equipo de Staff Administrativo. Está encabezada por su Subdirectora y por los Jefes de las Áreas de Reclutamiento y Selección y de Educación (Consejo de Alta Dirección P Åoblica, 2013).

- Actividades clave: como se ha mencionado y 
desarrollado ya anteriormente, las actividades claves del SADP corresponden a los diferentes subsistemas de gestión de recursos humanos que éste utiliza para la concreción de su propuesta de valor público. Así en ese sentido, sus actividades se desprenden de los subsistemas de planificación y soporte, gestión del desempeño y gestión del desarrollo, siendo estas: planificación y soporte, reclutamiento y selección, inducción, gestión del desempeño, desarrollo y desvinculación.

- Recursos clave: el desarrollo de las actividades clave del SADP hace necesario la disponibilidad de recursos que son claves para la propuesta de valor del mismo, tales como la plataforma tecnológica del Sistema de Postulación en Línea, y sus recursos humanos provenientes principalmente del área de la psicología, administración pública y derecho (Dotación efectiva de la DNSC a diciembre 2013: 111 personas (Dirección Nacional del Servicio Civil, 2014b)). Además, constituyen recursos claves el Convenio Marco por el cual el SADP externaliza los procesos de evaluación y búsqueda de candidatos a cargos de alta dirección pública suscrito para estos efectos por la Dirección Nacional del Servicio Civil y la Dirección de Compras y Contratación Pública, ChileCompra; y los convenios de desempeño suscritos entre el Alto Directivo y su superior jerárquico, los cuales consideran los programas de mejoramiento de gestión, las metas gubernamentales, la administración de los recursos presupuestarios y los compromisos específicos que contraiga el Directivo con la respectiva autoridad (Consejo de Alta Dirección P $\tilde{A}^{o}$ blica, 2013).

- Alianzas estratégicas: para el funcionamiento y perfeccionamiento del SADP, es necesario establecer y mantener relaciones estratégicas con una red de contactos externos, entre los cuales a partir del análisis de contexto y de actividades del SADP se pueden mencionar las empresas consultoras que intervienen en el proceso de reclutamiento y selección, la Presidencia de la República, los Ministros y Jefes de Servicios de los cargos adscritos al Sistema de Alta Dirección Pública, así como el Congreso Nacional quienes pueden emitir diferentes directrices para apoyar el funcionamiento del sistema.

- Fuentes de ingresos: Para hacer efectiva la propuesta de valor se requiere mantener y fortalecer las relaciones con los clientes para conseguir y rentabilizar fuentes de ingresos los cuales provienen principalmente del Presupuesto de la Nación mediante aporte fiscal, y del financiamiento por parte de Organismos Inter- nacionales (Banco Mundial, Banco Interamericano de Desarrollo, entre otros).

- Estructura de costos: también se debe controlar el coste de toda la estructura orientada a la creación de valor, el cual se genera principalmente con el proceso de reclutamiento y selección de candidatos a cargos adscritos al SADP, y con el pago de personal de la Dirección Nacional de Servicio Civil.

El modelo de negocio del SADP para concretar su propuesta de valor público consiste en dotar a las instituciones del gobierno central de equipos directivos altamente calificados para desempeñarse en la gestión pública, disminuyendo con ello la politización de la función pública.

\section{Cadena de Valor del Sistema de Alta Dirección Pública}

La cadena de valor, es una herramienta que nos permite dividir una organización en sus actividades estratégicamente relevantes a fin de entender su comportamiento en torno a la producción de valor y muestra además la forma en que esas actividades están conectadas entre sí. Las actividades de valor se dividen en dos grandes grupos: primarias y de apoyo. Las primarias, son las que intervienen directamente en la creación del valor. Las actividades de apoyo respaldan a las primarias y viceversa, al ofrecer insumos, tecnología, recursos humanos y diversas funciones globales (Porter, 1987).

Al aplicar el concepto de cadena de valor al sector público se obtiene fundamentalmente un modelo descriptivo cuyo potencial primordial radica en posibilitar una expresión simple y rigurosa de lo que es la cadena de valor público, y en tal sentido, ayuda entender y, en alguna medida, a "descubrir" las políticas y el accionar de la organización pública (Sotelo, 2012).

Partiendo de la estructura orgánica de la DNSC y de las actividades que se han identificado anteriormente como claves para el SADP como sistema de gestión de recursos humanos, se puede entonces identificar la cadena de valor público del mismo, de lo cual se obtiene lo siguiente:

La cadena de valor público del SADP, se activa con la solicitud de provisión del cargo realizada por el cliente, es decir, el respectivo Ministro (por requerimiento de la Presidencia de la República o del Jefe de Servicio, sea I o II Nivel Jerárquico según el caso) al Consejo de Alta Dirección Pública y por la construcción del perfil de selección en la que parti- 
cipa además la DNSC (Consejo de Alta Dirección P $\tilde{A}^{0}$ blica, 2013).

A partir de ello, se desarrollan las actividades primarias del SADP que corresponden a los subsistemas de gestión del desempeño y gestión del desarrollo, que dentro del proceso de la cadena de valor son: reclutamiento y selección, inducción, gestión del desempeño y desarrollo. En cuanto a la actividad de desvinculación, esta es la que da inicio a un nuevo proceso en la cadena de valor, por lo que no es considerada como parte del proceso de producción de un directivo publico idóneo para el cliente, sino más bien es una acción facultativa del cliente para solicitar un nuevo proceso, dando con ello lugar a la producción de un nuevo directivo público (Consejo de Alta Dirección PÃ oblica, 2013).

Las actividades primarias ejecutadas por el SADP, son acompañadas por las actividades de soporte desarrolladas por la estructura orgánica de la DNSC, correspondientes con el subsistema de planificación y soporte, las cuales dentro de la cadena de valor son: gestión de planificación y desarrollo, gestión jurídica, gestión de comunicaciones, gestión de auditorías internas, gestión de desarrollo de personas, gestión interna y gestión financiera.

Todas estas actividades en su conjunto posibilitan el producto final que se materializa en dotar a las instituciones del gobierno central de equipos directivos altamente calificados para desempeñarse en la gestión pública, disminuyendo con ello la politización de la función pública, dando así cumplimiento a la propuesta de valor público planteada por el SADP. De ésta forma, con la identificación de la cadena de valor público se puede visualizar cómo el SADP desarrolla y articula sus actividades, tanto primarias como de apoyo, en torno a la concreción de su propuesta de valor público.

\section{Diagnóstico institucional del Sistema de Alta Dirección Pública}

\section{Cargos adscritos al Sistema de Alta Dirección Pública}

Con la información disponible no fue posible aplicar el indicador "cargos adscritos al Sistema de Alta Dirección Pública", debido a que no se cuenta con los datos diferenciados de cargos adscritos y no adscritos al SADP en cada año, ni con el dato del total de cargos directivos por año en el gobierno central. Sin embargo, con la información disponible acerca del total de cargos en el SADP (adscritos y no adscritos) en cada año se puede obtener una visión del progreso en cobertura.

Así, al analizar la información, se observa una línea de tendencia alcista en cuanto al total de cargos en el SADP en cada año, lo cual proyecta hacía una mayor cobertura del SADP incrementando con ello la profesionalización y disminuyendo, consecuentemente, las designaciones basadas eminentemente en criterios políticos.

Cabe señalar que si bien se encuentran bajo la línea de tendencia los años 2005, 2006, 2013 y 2014, ello se explica en razón de diversos factores. En el año 2005 no se incorporan cargos por lo que no se dan movimientos en la tendencia. Posteriormente en el año 2006 se da un leve incremento, pero pese a ello, figura como el mayor punto de ruptura. Esto se debe a que el año 2007 sucedieron una serie de hechos con amplia cobertura mediática que ponían en tela de juicio la honestidad de las autoridades públicas (Mardones, 2008). Por ello que la Presidenta Michelle Bachelet aceleró el proceso de incorporación de los cargos previstos por la Ley al Sistema de Alta Dirección Pública, llegando a 101 servicios, y la incorporación de otros cargos que incomprensiblemente no habían sido previstos en la Ley (Lafuente et al., 2013). La incorporación acelerada de los cargos causa que exista la brecha entre el año 2006 y 2007 generando con ello la ruptura en la línea de tendencia.

Por otra parte, el comportamiento en los años 2013 y 2014 es atribuible al mismo avance de la cobertura del Sistema, en el sentido de que las variaciones por año tenderán a ser cada vez menores según se avance, pues habrá menos servicios para incorporar al SADP.

\section{Atracción de nuevos candidatos}

$\mathrm{Al}$ aplicar el indicador "atracción de nuevos candidatos" al período 2004-2014, se observa una la línea de tendencia alcista, lo cual indica que la capacidad del SADP para atraer nuevos postulantes a ser incorporados a la función pública bajo criterios de mérito e idoneidad tenderá a ir en aumento. Ello es positivo para el Sistema, pues el incremento de postulantes promoverá la apertura de los procesos evitando la arbitrariedad, la politización y las prácticas de patronazgo o clientelismo.

Sin embargo, es importante señalar que existen algunos puntos de ruptura por debajo de la misma, los cuales corresponden a los años 2005 con un promedio de 68.27 postulantes por concurso; 2008 con 104.96; 2009 con 83.51; 2011 con 103.66 y 2014 con 


\subsection{9 postulantes por concurso.}

Se observa que en el año 2005, la tasa de crecimiento en relación al período anterior, para el número de postulantes fue de $171 \%$, mientras que para los concursos fue de $438 \%$, y la razón entre ambos fue de 0.39. Ello indica que el crecimiento en el número de concursos efectuados ha sido mayor en relación al crecimiento en el número de postulantes, lo cual implica una reducción en el promedio de postulantes por concurso, produciendo con ello la ruptura en la línea de tendencia.

Para el año 2008, la tasa de crecimiento del número de postulantes fue de $-3 \%$, mientras que para los concursos fue de $29 \%$, y la razón entre ambos fue de -0.1. Ello refleja un decrecimiento en el número de postulantes, mientras por otra parte se ha dado un crecimiento en el número de concursos efectuados, lo cual implica una reducción en el promedio de postulantes por concurso, produciendo con ello la ruptura en la línea de tendencia.

En el año 2009, la tasa de crecimiento del número de postulantes fue de $-2 \%$, mientras que para los concursos fue de $23 \%$, y la razón entre ambos fue de -0.1. Ello, al igual que en el año 2008, indica un decrecimiento en el número de postulantes, mientras por otra parte se ha dado un crecimiento en el número de concursos efectuados, lo cual implica una reducción en el promedio de postulantes por concurso, produciendo con ello la ruptura en la línea de tendencia.

Para el año 2011, la tasa de crecimiento del número de postulantes fue de $18 \%$, mientras que para los concursos fue de $56 \%$, y la razón entre ambos fue de 0.31. Ello, al igual que en el año 2005, indica que el crecimiento en el número de concursos efectuados ha sido mayor en relación al crecimiento en el número de postulantes, lo cual implica una reducción en el promedio de postulantes por concurso, produciendo con ello la ruptura en la línea de tendencia.

Finalmente, para el año 2014, la tasa de crecimiento del número de postulantes fue de $-44 \%$, mientras que para los concursos fue de $-13 \%$, y la razón entre ambos fue de 3.49. Ello refleja un decrecimiento mayor en el número de postulantes en relación al decrecimiento en el número de concursos efectuados, lo cual implica una reducción en el promedio de postulantes por concurso, produciendo la ruptura en la línea de tendencia.

\section{Candidatos del sector privado}

En relación a los datos para identificar los postulantes provenientes del sector privado, según la información proporcionada por la Dirección Nacional del Servicio Civil, únicamente ha sido posible diferenciar la procedencia de algunos postulantes de ese sector a partir del año 2008.

Al aplicar el indicador "candidatos del sector privado" con la información disponible para el período 2008-2014, se observa una la línea de tendencia alcista, lo cual indica que la capacidad del SADP para atraer candidatos del sector privado con experiencia e idoneidad para el sector público tenderá a ir en aumento. Esto es positivo para el Sistema, pues el incremento de postulantes promoverá la apertura de los procesos evitando la arbitrariedad, la politización y las prácticas de patronazgo o clientelismo, y permitirá además incorporar técnicas y conocimientos del sector privado al sector público, promoviendo además con ello la innovación en la gestión pública.

Sin embargo, es importante señalar que existen algunos puntos de ruptura por debajo de la misma, los cuales corresponden a los años 2008 con un promedio de 0.0044 postulantes del sector privado por concurso; 2009 con 12.6643 y 2014 con 57.7135 postulantes del sector privado por concurso.

El año 2008, es el primer año en el cual se logran identificar postulantes del sector privado, habiendo sido identificado 1 postulante del sector privado, y 228 los concursos efectuados. Ello explica el promedio de 0.0044 .

Para el año 2009, la tasa de crecimiento en relación al período anterior, para el número de postulantes del sector privado fue de $354500 \%$, debido a que en ese año se lograron identificar más postulantes provenientes de ese sector en los registros de datos, mientras que para los concursos fue de $23 \%$, y la razón entre ambos fue de 15543.46. Ello indica que el crecimiento en el número de concursos efectuados ha sido mayor en relación al crecimiento en el número de postulantes del sector privado identificados, lo cual implica una reducción en el promedio de postulantes por concurso, produciendo con ello la ruptura en la línea de tendencia.

Por último, para el año 2014, la tasa de crecimiento del número de postulantes del sector privado identificados fue de $-43 \%$, mientras que para los concursos fue de $-13 \%$, y la razón entre ambos fue de 3.39. Ello refleja un decrecimiento mayor en el número de postulantes del sector privado en relación al decrecimiento en el número de concursos efectuados, lo cual implica una reducción en el 
promedio de postulantes por concurso, produciendo con ello la ruptura.

\section{Candidatos del sector público}

Únicamente ha sido posible diferenciar la procedencia de algunos postulantes del sector público a partir del año 2009. Al aplicar el indicador "candidatos del sector público" con la información disponible para el período 2009-2014, se obtiene una línea de tendencia alcista. Esto indica que la capacidad del SADP para atraer candidatos del sector público con experiencia e idoneidad tenderá a ir en aumento, lo cual es positivo para el Sistema, pues el incremento de postulantes promoverá la apertura de los procesos evitando la arbitrariedad, la politización y las prácticas de patronazgo o clientelismo, y permitirá además disminuir la fuga de talentos del sector público hacia el sector privado.

Sin embargo, es importante señalar que existen algunos puntos de ruptura por debajo de la misma, los cuales corresponden a los años 2009 con un promedio de 7.65 , y 2014 con 38.19 postulantes del sector privado por concurso.

El año 2009, es el primer año en el cual se logran identificar postulantes del sector público, habiendo sido identificados 2,141 postulante del sector público y siendo 228 los concursos efectuados. Ello explica el promedio de 7.65 que se toma como punto inicial y que produce la ruptura en la línea de tendencia, pues en los años subsiguientes la identificación de procedencia de los postulantes en el registro de datos mejora considerablemente.

Por otra parte, para el año 2014, la tasa de crecimiento del número de postulantes del sector público identificados fue de $-41 \%$, mientras que para los concursos fue de $-13 \%$, y la razón entre ambos fue de 3.20. Ello refleja un decrecimiento mayor en el número de postulantes del sector público en relación al decrecimiento en el número de concursos efectuados, lo cual implica una reducción en el promedio de postulantes por concurso, produciendo con ello la ruptura en la línea de tendencia.

\section{Procesos que finalizan con entrega de nómina de candidatos}

Al aplicar el indicador "procesos que finalizan con entrega de nómina de candidatos" al período 2004-2014 sobre los datos de los procesos que finalizan con entrega de nómina de candidatos en cada año y de los concursos convocados por año de acuerdo a la fecha de inicio de publicación, se observa una línea de tendencia levemente alcista. Esto indica que la capacidad del SADP para generar nóminas de candidatos idóneos, en base a criterios de mérito, que cubran la demanda de los clientes para la gestión pública, tenderá a un crecimiento progresivo lento pero estable. Ello es positivo para el Sistema pues genera credibilidad y legitimidad por su eficacia en la producción de nóminas de candidatos idóneos, con lo cual la autoridad puede elegir entre diferentes opciones a aquella que satisfaga sus requerimientos.

No obstante, es importante señalar que existen algunos puntos principales de ruptura por debajo de la misma, los cuales corresponden a los años 2005 con un $42 \%$ de procesos que finalizan con entrega de nómina respecto a los convocados, y el 2014 con un $27 \%$. Sin embargo, no es posible identificar las causas de los puntos de ruptura a partir de la información disponible para el estudio.

\section{Procesos que finalizan con nombra- miento de directivos}

$\mathrm{Al}$ aplicar el indicador "procesos que finalizan con nombramiento de directivos" al período 20042014 sobre los datos de los procesos con nombramiento de directivos en el año t y de los concursos convocados por año de acuerdo a la fecha de inicio de publicación, se observa una la línea de tendencia alcista, lo cual indica que la capacidad del SADP para proveer directivos idóneos de acuerdo a los criterios de mérito y confianza política requeridos por los clientes, tenderá a un crecimiento progresivo. Ello es positivo para el Sistema pues genera credibilidad y legitimidad por su eficacia en incorporar directivos públicos idóneos para la gestión pública.

Es importante señalar que existen algunos puntos de ruptura por debajo de la línea de tendencia, los cuales corresponden a los años 2004 con $50 \%$ de procesos que finalizan con nombramiento de directivos respecto a los convocados; 2005 con un $38 \%$; 2010 con un $57 \%$ y 2014 con un $16 \%$. Para los años 2004 y 2005 podría deberse al mismo proceso de adaptación de pasar de un sistema de designación en base a criterios de confianza a uno que prioriza el mérito. Por otra parte, los años 2010 y 2014 coinciden con períodos de cambio de gobierno lo cual es indicativo de que los criterios políticos toman mayor peso en ese tipo de coyunturas, por lo que habría que fortalecer el Sistema para responder de mejor forma ante ese tipo de escenarios. 


\section{Procesos declarados desiertos}

$\mathrm{Al}$ aplicar el indicador "procesos declarados desiertos" al período 2004-2014 sobre los datos de los concursos declarados desiertos y de los concursos convocados por año de acuerdo a la fecha de inicio de publicación, se observa una la línea de tendencia alcista, lo cual indica que el número procesos que no finalizan satisfactoriamente con propuesta y selección de candidatos por no satisfacer criterios de idoneidad y/o de confianza política tiende al alza. Esto es un llamado de atención pues podría dañar la credibilidad en el Sistema, pues su objetivo es dotar a la administración pública de directivos idóneos para la gestión pública, por lo que se espera que los concursos finalicen con nombramiento de directivo, y el hecho de que los procesos concluyan con declaración de desierto evita que se cumpla dicho objetivo.

Existen algunos puntos por encima de la línea de tendencia que sobresalen de forma considerable, los cuales corresponden a los años 2007 con $40 \%$ de procesos declarados desiertos respecto a los convocados; 2009 con un $34 \%$ y 2013 con un $34 \%$.

Para identificar posibles líneas de análisis sobre las causas de las alzas en los porcentajes de concursos declarados desiertos en relación a los convocados en el año se verifica la información explicitada en el figura 1.

Se observa que el mayor número de concursos desiertos han sido declarados por los Comité de Selección, con un total de 302 concursos declarados desiertos, mientras que por el CADP han sido declarados desiertos 16, y por la Autoridad 254 concursos. Respecto a los puntos sobresalientes en la tendencia del gráfico 11, se observa que para el 2007, un total de 71 concursos fueron declarados desiertos; 44 fueron declarados desiertos por los Comités de Selección; 2 por el CADP, y 25 por la Autoridad. En el año 2009, un total de 96 concursos fueron declarados desiertos; 79 por los Comités de Selección; 1 por el CADP, y 16 por la Autoridad. Finalmente en el año 2013, fueron declarados desiertos un total de 73 concursos; 24 por los Comités de Selección; ninguno por el CADP, y 49 por la Autoridad. Por otra parte, es importante además observar las líneas de tendencia de los concursos declarados desiertos en el gráfico 12, pues mientras que la tendencia del CADP es levemente bajista, reflejando mayor estabilidad, tanto la línea de tendencia de los Comités de Selección como de la Autoridad son alcistas, con una mayor tendencia de crecimiento en la Autoridad. Esto podría dar indicios de arbitrariedad, politización y de prácticas de patronazgo o clientelismo dentro de los procesos de reclutamiento y selección, afectando con ello la credibilidad y legitimidad del sistema, así como la eficacia en el cumplimiento de sus objetivos. Por tanto, es importante profundizar en próximos estudios acerca de las causas o fundamentos por los cuales son declarados desiertos los concursos por parte de las entidades, principalmente por los Comités y las Autoridades.

\section{Directivos provisionales}

En relación a los datos sobre el número de personas que, encontrándose desempeñando el cargo de forma provisional, fueron nombrados como directivos, del total de nombramientos efectuados, según la información proporcionada por la Dirección Nacional del Servicio Civil, únicamente ha sido posible identificarlos a partir del año 2010. Al aplicar el indicador "directivos provisionales" al período 20102014, se observa una línea de tendencia bajista, lo cual indica que el número de nombramientos de directivos que ya se encontraban desempeñando provisionalmente el cargo tenderá a disminuir.

Sin embargo, los porcentajes obtenidos en los diferentes años son altos, principalmente para el 2011 , 2012 y 2013, los cuales presentan un $51 \%$, $45 \%$ y $53 \%$ respectivamente. Ello es un llamado de atención pues podría dañar la credibilidad y legitimidad del Sistema, ya actualmente existe una percepción de que existen privilegios en los procesos de reclutamiento y selección para aquellos que ya se encuentran desempeñando los cargos como provisionales y transitorios, pues son los que en su mayoría resultan nombrados (Castañeda, 2014), lo cual se constanta según los datos presentados.

Lo anterior concuerda con las principales críticas que se expresaron al efectuarse el cambio de coalición en el gobierno, asumiendo el Presidente Piñera, las cuales se centraron en lo referente al nombramiento de gran cantidad de provisionales y transitorios (Egaña, 2011). Sin embargo, con la información disponible, no es posible profundizar sobre las causas probables de los elevados porcentajes en el nombramiento de directivos que ya se encontraban desempeñando el cargo como provisionales y transitorios, por lo que debe considerarse su abordaje en próximos estudios.

\section{Desarrollo de perfiles}

El artículo cuadragésimo octavo de la Ley No 19.882 del Nuevo Trato laboral (Ministerio de Hacienda, 2003) establece entre los requisitos para convocar a un proceso de selección la definición del perfil profesional para el cargo, y de las competencias y aptitudes requeridas para desempeñarlo. Por 
Figura 1: Análisis de rupturas de "procesos declarados desiertos"

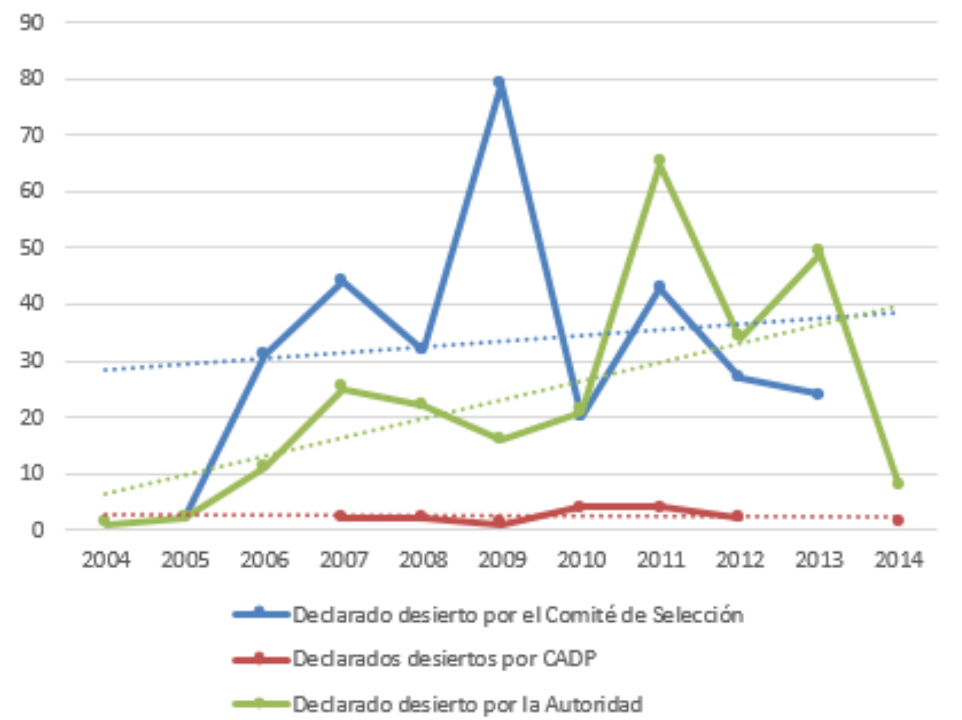

Fuente: Elaboración propia

tanto, todos los cargos directivos adscritos al SADP para los cuales se ha efectuado concurso poseen un perfil desarrollado previo a ser convocados.

El perfil profesional, de competencias y aptitudes del alto directivo público en el caso del I nivel, es definido por el Ministro respectivo y propuesto al Consejo de Alta Dirección pública en una sesión del mismo Consejo. En el caso del II nivel, el perfil es definido por el jefe de servicio y discutido por un comité de selección, compuesto por un representante del jefe de servicio, un representante del ministerio y por un profesional representante del Consejo de Alta Dirección Pública. Estos perfiles son luego enviados a la Dirección Nacional del Servicio Civil para su registro. Actualmente los perfiles publicados contienen requisitos legales (educación universitaria, experiencia previa comprobable), misión del cargo, contexto del cargo, entre otros (Centro de Políticas P $\tilde{A}^{\text {oblicas }}$ UC, 2013).

Por ello, no es necesario aplicar el indicador pues el resultado para cada año del período 2004-2014 sería del $100 \%$. Sin embargo, es posible afirmar entonces, que los perfiles para los cargos adscritos al SADP consideran las competencias claves para el éxito en el desempeño del puesto.

\section{Actualización de perfiles}

No ha sido posible aplicar el indicador "actualización de perfiles" a partir de la información disponible para el estudio, debido a que no se cuenta con el dato acerca de cuáles son los cargos que se han concursado por año, ni tampoco se encuentran diferenciados el número de cargos adscritos y no adscritos existentes en SADP en cada año.

Sin embargo, la aplicación del ya mencionado artículo cuadragésimo octavo de la Ley No 19.882 del Nuevo Trato laboral (Ministerio de Hacienda, 2003) permite afirmar que el SADP actualiza los perfiles cada vez que se convoca a concurso el cargo, por lo que se incorporan criterios de idoneidad acordes a los cambios y a las nuevas exigencias de la gestión pública.

\section{Cargos directivos con titulación uni- versitaria}

El artículo cuadragésimo de la Ley No 19.882 del Nuevo Trato laboral (Ministerio de Hacienda, 2003), establece entre los requisitos para ejercer un cargo de alta dirección pública el poseer un título de una carrera de, a lo menos, 8 semestres de duración, otorgado por una universidad o instituto profesional del Estado o reconocidos por éste. Ello ocasiona que el número de directivos del SADP con titulación universitaria nombrados al año sea igual al total de directivos del SADP nombrados, razón por la cual no es necesario aplicar el indicador pues el resultado para cada año del período 2004-2014 sería del $100 \%$.

Por tanto, es posible afirmar que la tecnificación de las plantillas públicas en relación a directivos con título de grado es de un $100 \%$, lo cual promueve el criterio de competencia técnica en la gestión pública. 


\section{Cargos directivos con titulación uni- versitaria de postgrado}

Respecto a los datos para identificar el número de directivos con titulación universitaria de postgrado nombrados cada año en relación al total de nombramientos por año, según la información proporcionada por la DNSC, únicamente ha sido posible diferenciarlos a partir del año 2008.

$\mathrm{Al}$ aplicar el indicador "cargos directivos con titulación de postgrado" con la información disponible para el período 2009-2014, se observa una línea de tendencia alcista. Ello indica que la tecnificación de las plantillas públicas en relación a los directivos públicos con título de postgrado irá en aumento, lo cual constata la capacidad del Sistema para incrementar la competencia técnica en la gestión pública.

Si bien se identifican algunos puntos por debajo de la línea de tendencia como lo son el año 2009, 2013 y 2014, estos no son críticos, pues al verificar con más detalle la información, se observa que el punto más bajo correspondiente al año 2009 se debe a que para ese año, de un total de 180 nombramientos no fue posible obtener información sobre el nivel de postgrado de 171, lo cual explica el bajo porcentaje el cual incide aumentando la inclinación de la línea de tendencia. Por otra parte, respecto a los puntos correspondientes para el año 2013 y 2014, se observa que la distancia no es significativa pues sus porcentajes se encuentran próximos a los demás puntos en la línea de tendencia.

\section{Desvinculaciones}

Debido a que no es posible aplicar el indicador "desvinculaciones" solo para los cargos adscritos al SADP pues en la base de datos no se encuentran desagregados por adscritos y no adscritos al SADP por año, se sustituye la formula $\left(\mathrm{N}^{\circ}\right.$ de directivos adscritos al SADP desvinculados en el año $t$ / No Total de cargos directivos adscritos al SADP en el año t)*100 por la formula $\left(\mathrm{N}^{\circ}\right.$ de directivos nombrados por SADP desvinculados en el año $t$ / No Total de directivos en el SADP en el año t)*100.

Así, el indicador se aplica desde el año 2005, año en el cual se registra la primera desvinculación, hasta el año 2014, y se observa una línea de tendencia alcista, lo cual indica que la cantidad de desvinculaciones tanto por solicitud de la autoridad como por renuncia de los directivos públicos tiende a aumentar.

$\mathrm{Al}$ verificar los puntos de ruptura por sobre la línea de tendencia, se observa que éstos correspon- den a los años 2005 con $0.24 \%$ de directivos desvinculados en relación al total de cargos directivos concursables por SADP; 2006 con $1.56 \%$; 2010 con $23.19 \%$ y $201432.45 \%$ directivos desvinculados. A excepción del 2005, en el cual se registra la primera desvinculación, los puntos corresponden a años en los cuales ocurrió un cambio de gobierno. En el año 2006 se da la transición de Ricardo Lagos a Michelle Bachelet; en el 2010, de Michelle Bachelet a Sebastián Piñera; y en el 2014 de Sebastián Piñera a Michelle Bachelet. Ello concuerda con la percepción de abuso en el ejercicio de la facultad de efectuar desvinculaciones (Castañeda, 2014), y es indicio de que existen despidos o rescisiones de empleo que, afectando a puestos de trabajo de carácter profesional, se deben a meras razones de cambio del liderazgo político en los gobiernos, lo cual es dañino para la legitimidad y credibilidad del Sistema.

\section{Nuevas incorporaciones}

Al aplicar el indicador "nuevas incorporaciones" al período 2004-2014 sobre los datos de directivos nombrados, que no ocupaban el cargo, en relación al total de directivos nombrados por año, se observa una línea de tendencia levemente bajista. Ello indica que el Sistema logra un balance adecuado entre estabilidad e innovación en la gestión pública, manteniendo con ello una buena capacidad de atracción de candidatos idóneos pues envía un mensaje de que se promueve el ingreso de personas nuevas pero también premia con la continuidad a aquellos que se desempeñan con éxito en el cargo.

$\mathrm{Al}$ verificar los puntos de ruptura, sobresalen considerablemente los correspondientes a los años 2004, 2007, 2008 y 2014. Como factores causales de este comportamiento se señala que en el año 2004 se implementa propiamente el SADP con la incorporación de 417 cargos (adscritos y no adscritos) lo cual explica el porcentaje elevado de las nuevas incorporaciones. Para los años 2007 y 2008 se perfila como posible causa la aceleración del proceso de incorporación de los cargos, efectuada por la Presidenta Bachelet (Lafuente et al., 2013).

Finalmente para el 2014, se visualiza como causa probable el cambio de coalición gobernante y el alto número de desvinculaciones, lo cual posibilitó la incorporación de nuevos directivos a los cargos adscritos al SADP (Castañeda, 2014).

\section{Continuidad}

De acuerdo a la información brindada por la DNSC, se identifican directivos renovados en su 
mandato a partir del año 2007. Al aplicar el indicador "continuidad" al período 2007-2014 sobre los datos de directivos renovados en su mandato y directivos desvinculados por año, se observa una línea de tendencia bajista, lo cual indica que el Sistema se proyecta a continuar desvinculando más directivos que los que son renovados en su mandato. Ello afecta la capacidad del SADP para generar estabilidad e incentivar el rendimiento y la participación de profesionales idóneos para la gestión pública, pues refleja pocas oportunidades para generar carrera en la gerencia pública.

Cabe destacar que los puntos más bajos corresponden a los años 2010, con una razón de $1 / 5$, y 2014 con una razón de 1/6. Ambos años coinciden con cambios en la coalición de gobierno, por lo que se percibe una menor posibilidad de ser renovado frente a la ocurrencia de éste tipo de eventos, lo cual debe ser analizado con mayor profundidad en próximos estudios.

\section{Compresión vertical de los salarios}

Con la información disponible, no fue posible aplicar el indicador "comprensión vertical de los salarios". Sin embargo, en base al análisis de la equidad interna realizado por la Dirección Nacional del Servicio Civil (Dirección Nacional del Servicio Civil, 2014a) el cual permite verificar, de acuerdo con la valoración de cargos de I y II Nivel Jerárquico, la consistencia interna que poseen las remuneraciones, se puede constatar que existe una descompresión significativa entre las remuneraciones del I Nivel Jerárquico en relación a las del II Nivel Jerárquico lo cual puede ser síntoma de captura del sistema por algunas élites y de un grado más o menos alto de inequidad interna de la estructura de compensación. Esto reduce los incentivos de carrera y el estímulo al rendimiento.

\section{Sueldo gubernamental promedio en la Alta Dirección Púbica / Sueldo pro- medio del sector privado}

Con la información disponible, no fue posible aplicar el indicador "sueldo gubernamental promedio en la Alta Dirección Púbica / Sueldo promedio del sector privado". No obstante, en base al análisis de competitividad externa desarrollado por la Dirección Nacional del Servicio Civil (Dirección Nacional del Servicio Civil, 2014a) es posible verificar que la tendencia de las remuneraciones es que a medida que se avanza en la escala jerárquica, disminuye la competitividad de las remuneraciones, disminuyendo con ello los estímulos para el rendimiento, dificultando además, bajo esta perspectiva, la atracción de talentos ejecutivos desde el sector privado al sector público.

\section{Conclusiones y recomendacio- nes}

Respondiendo a los objetivos planteados en la investigación, se ha podido constatar, a través de la metodología aplicada, que efectivamente el Sistema de Alta Dirección Pública en Chile ha conseguido captar la propuesta del CLAD de compatibilizar la profesionalización de los sectores fundamentales de la burocracia con el aumento de la responsabilización de los funcionarios públicos ante la sociedad y el sistema político, logrando con ello disminuir la politización de la función pública.

Se observó que el SADP utiliza como actividades claves para la producción su valor público: la planificación y soporte, reclutamiento y selección, inducción, gestión del desempeño, desarrollo y desvinculación. Actividades que se desprenden de los subsistemas de planificación y soporte, gestión del desempeño y gestión del desarrollo, siendo los directamente involucrados en la promoción del mérito y de la capacidad funcional los dos últimos.

Así, al aplicar los indicadores elaborados a ámbitos propios de los subsistemas de gestión del desempeño y gestión del desarrollo para medir en que forma el SADP promueve el mérito y la capacidad funcional para cumplir con su propuesta de valor, se pudo constatar que en términos generales, ambos subsistemas contribuyen positivamente a la concreción de la propuesta de valor y a la disminución de la politización de la función pública, principalmente a través del avance en la cobertura del sistema, la atracción de nuevos candidatos (tanto del sector privado como del sector público), la producción de nóminas y nombramiento de directivos, la disminución de designación de provisionales y transitorios, el desarrollo y actualización de perfiles, y en la tecnificación de las plantillas.

Cabe señalar que parte importante del buen desempeño del SADP responde a un largo proceso de reforma y modernización del Estado en Chile, que con diversos matices durante los diferentes períodos de gobierno, ha logrado sentar las bases para una sólida institucionalidad. Sin embargo, ella no está exenta de riesgos, pues sigue afrontando los desafíos que le han sido propios desde los inicios de su historia (path dependence) y que siguen siendo determinantes para el desarrollo futuro tanto del 
SADP como de la institucionalidad chilena.

Esta dependencia de la trayectoria en el desarrollo institucional ha sido evidenciada en el estudio, ya que el análisis revela que es posible fortalecer algunos aspectos del SADP en los que se han verificado ciertas debilidades en relación a lo planteado por el CLAD, las cuales podrían afectar la concreción de su propuesta de valor público.

Por ejemplo, en relación al funcionamiento del SADP como sistema de gestión de recursos humanos, de los subsistemas contemplados en el modelo de gestión de personas únicamente es posible aplicar los de planificación y soporte, gestión del desempeño y gestión del desarrollo, y no así el de gestión del cambio organizacional, el cual es fundamental para realizar las transformaciones necesarias para orientar a la organización, en su conjunto, hacia los horizontes de largo plazo vinculados a la misión institucional, considerando contextos cambiantes.

Esto mismo sucede, aunque en menor medida, con el subsistema planificación y soporte, el cual se ve afectado por la rigidez normativa al momento de intentar amplificar el aporte de la gestión de personas a la estrategia institucional para soportar de mejor manera la operación del Sistema en conjunto. Ante esta cuestión que afecta a ambos subsistemas, se recomienda fortalecer los canales de comunicación entre las entidades rectoras del SADP (CADP y DNSC) y los aliados estratégicos del modelo de negocio (Presidencia de la República, Ministros, Jefes de Servicios y Congreso Nacional) quienes pueden emitir diferentes directrices para flexibilizar el marco normativo y apoyar así la mejora en su funcionamiento.

Además, con el diagnóstico efectuado, se observa que en relación al subsistema de gestión del desempeño, llaman la atención los resultados respecto a los procesos declarados desiertos, las desvinculaciones, y las nuevas incorporaciones. La tendencia alcista en el número de procesos declarados desiertos (especialmente por los Comités y la Autoridad) y en el número de desvinculaciones, y la levemente bajista en las nuevas incorporaciones, indican que, pese al gran avance del SADP, aún persisten algunos rasgos clientelares que no han sido superados pues tienen su raíz en el path dependence del desarrollo institucional chileno, por lo cual requerirán de un mayor esfuerzo para su disminución.

Según el estudio, la mayor causa de desvinculaciones responde a criterios puramente de confianza política, especialmente frente a escenarios de cambio de gobierno. Por tal motivo se sugiere, ante esos escenarios, establecer un período de prueba de 6 meses para los directivos públicos, después del cual se rinda un informe en el que la Autoridad, en base a criterios técnico-políticos se pronuncie en relación a la continuidad del directivo público, y que dicho informe posteriormente sea sometido a conocimiento del CADP para que ratifique o modifique la decisión de la autoridad, y en caso de existir contradicción entre la opinión de la autoridad y el CADP, sería la Contraloría General de la República quien sumariamente dirimiría la controversia. Así se establece un sistema de pesos y contrapesos que garantiza criterios técnicos y políticos en la designación de los directivos públicos, propiciando una mayor estabilidad al director público, lo que contribuirá finalmente a hacer más atractivo al sistema y por lo tanto mejor su funcionamiento.

Por otra parte, en cuanto al nombramiento de provisionales y transitorios, si bien se observa una tendencia bajista, el estudio indica que aún existe una percepción de abuso en el uso de esta figura, por lo que para dotarla de mayor credibilidad y legitimidad, se sugiere que éstos sean designados de entre la última nómina de candidatos propuesta para el cargo, y en caso que ninguno de ellos aceptase, se seleccione de una bolsa de candidatos ya sometidos a concursos. Por lo que se sugiere además la creación de una bolsa de candidatos, la cual estaría conformada por aquellos que ya han participado anteriormente de procesos de reclutamiento y selección y han sido incorporados en las nóminas para los cargos a los que han concursado.

Adicionalmente, se observa que en el subsistema de gestión del desarrollo, la tendencia bajista en la continuidad de directivos, la descompresión significativa entre las remuneraciones de I y II Nivel Jerárquico, y la disminución de su competitividad respecto a las del sector privado a medida que se avanza en la escala jerárquica, sumado a la carencia de movilidad, reflejan una limitante en la capacidad del sistema para incentivar el rendimiento y el desarrollo profesional de los directores públicos. Por ello, se sugiere incorporar aspectos de un sistema de carrera de forma que se permita tanto la movilidad como el desarrollo de carrera en la alta dirección pública, dotando con ello al SADP de mayor estabilidad y capacidad de atracción de candidatos idóneos, tanto del sector público como del privado.

Se debe construir un modelo que considere elementos claves de una organización, tales como una estrategia o política pública clara, capacidad de gestión interna y un entorno apropiado que autorice y/o favorezca la gestión de la política pública definida, recordando además que es deber del director público actuar en estos tres ámbitos o áreas para conseguir el impacto deseado de la política pública. Esto permitirá al SADP generar directivos públicos 
que no sean solamente técnicos sino más bien que sean verdaderos estrategas en la gestión pública, incorporando en sus actividades una reflexión sustantiva sobre lo que es valioso y eficaz, un diagnóstico de las expectativas políticas, y análisis detallados de lo que es viable operativamente, integrando de esa forma la dimensión política, la dimensión sustantiva y la dimensión administrativa.

Es necesario mencionar que la aplicación de la metodología presenta algunos desafíos en el "análisis de eficacia funcional", pues el modelo de gestión del empleo y los recursos humanos del sistema analizado puede diferir del modelo utilizado. Además, la forma en que se registran y almacenan los datos en las entidades rectoras no siempre coincidirá o será suficiente para emplear los indicadores presentados, por lo que estos aspectos deben tenerse en consideración al momento de ser aplicada en próximas investigaciones.

Pese a ello, es claro que dar continuidad a estos procesos desde el ámbito de la academia y de la investigación, sistematizando sus experiencias y evaluando sus resultados e impactos, resulta de vital importancia, y desde esa perspectiva el presente estudio pretende haber efectuado una contribución, de forma que sirva como insumo para futuros esfuerzos que se orienten a profundizar sobre los procesos de reforma y modernización del Estado en los diferentes países de Latinoamérica.

\section{Referencias}

Aguilar, L. (2006). Gobernanza y gestión pública. Fondo de Cultura Económica, México D.F.

Araya, E. y Cerpa, A. (2008). La nueva gestión pública y las reformas en la administración pública chilena. Tékhne-Revista de Estudos Politécnicos, VII(11):19-47.

Arenilla, M. (2010). Administración pública y ciencia de la administración. En Arenilla, M., editor, Administración pública y ciencia de la administración, pp. 39-68. Instituto Nacional de Administración Pública, Madrid.

Barozet, E. (2006). Relecturas de la noción de clientelismo: una forma diversificada de intermediación política y social. Debate, (69):77-102.

Bonnefoy, J. y Armijo, M. (2005). Indicadores de desempeño en el sector público. CEPAL, Santiago de Chile.

Castañeda, L. (2014). Alta Dirección Pública evalúa perfeccionar el sistema y establecer límites a desvinculaciones. El Mercurio blogs.
Catalá, R. (2005). Directivos públicos. Presupuesto y Gasto Público, (41):211-225.

Centro de Políticas P Ãôoblicas UC (2013). Informe Final. Convenios de Desempeño. Rediseño de los convenios de desempeño de los altos directivos públicos. Technical report, Santiago.

Consejo de Alta Dirección P $\tilde{A}^{\text {ô}}$ blica (2013). Memoria 2011-2012. Consejo de Alta Dirección Pública. Technical report, Santiago.

Corcuera, J. (2001). Naturaleza del trabajo directivo (una universidad moderna de los temas clásicos) y su repercusión en los programas de formación en dirección de empresas. Tesis doctoral, IESE Business School (Universidad de Navarra).

Cortázar, J. C. (2011). Aprendiendo a partir de la reforma del Servicio Civil en Chile. Algunas lecciones de interés para países latinoamericanos. Reforma y Democracia, (49):1-14.

Díaz, A. (2011). Excelencia y creación de valor para una gestión pública inteligente. Revista Vasca de Gestï $\frac{1}{2} n$ de Personas y Organizaciones $P \ddot{z} \frac{1}{2} b l i$ cas, (1):35-52.

Dirección Nacional del Servicio Civil (2014a). Balance de gestión integral año 2013. Technical report, Santiago.

Dirección Nacional del Servicio Civil (2014b). Informe final: Equidad Interna, competitividad externa, escenarios de asignación ADP. Santiago.

Echebarría, K. y Cortázar, J. C. (2007). Las reformas de la administración y el empleo públicos en América Latina. En Lora, E., editor, El estado de las reformas del Estado en América Latina, pp. 139-173. Banco Mundial, Banco Interamericano de Desarrollo y Mayol Ediciones, Washington, D.C.

Echebarría, K. y Mendoza, X. (1999). La especificidad de la gestión pública: El concepto de management público. En Losada, C., editor, $\hat{A}_{\dot{\zeta}} D e$ burócratas a gerentes? Las ciencias de la gestión aplicadas a la Administración del Estado, pp. 15-46. Banco Interamericano de Desarrollo, Washington D.C.

Egaña, R. (2011). Â¿Tapados en la Alta Dirección Pública? Instituto de Asuntos Públicos. Universidad de Chile.

Freidenberg, F. (2015). ¡ en tierra de caciques! liderazgos populistas y democracia en ecuador. OPE$R A, 16(16): 99-130$.

Iacoviello, M. y Essayag, S. (2011). El desafío de profesionalizar la función pública en América Latina. San José. PNUD. 
Lafuente, M. (2011). Experiencias comparadas en Alta Dirección Pública. Modelo de gestión de desempeño, rentas e incentivos. En Seminario Internacional sobre Alta Dirección Pública 2011, pp. 36-40. DNSC, Santiago.

Lafuente, M., Schuster, C., y Rojas-Wettig, M. (2013). Dinámicas, condicionantes políticas y enfoques viables de reformas del servicio civil: Lecciones de América Latina. En VIII Congreso Internacional del CLAD sobre la Reforma del Estado y de la Administración Pública, pp. 1-20, Montevideo. CLAD.

Levitt, B. y March, J. G. (1988). Organizational learning. Annual review of sociology, pp. 319340 .

Longo, F. (2002a). Institucionalizar la gerencia pública: Retos y dificultades. En Primer Congrès Català de Gestió Pública, Barcelona. Congrès Català de Gestió Pública.

Longo, F. (2002b). Marco analítico para el diagnóstico institucional de sistemas de servicio civil. Banco Interamericano de Desarrollo, Barcelona.

Losada, C. (1999). Âं $\hat{A}_{\dot{ }}$ e burócratas a gerentes? Las ciencias de la gestión aplicadas a la administración del Estado. Banco Interamericano de Desarrollo, Washington D.C.

Magretta, J. y Stone, N. (2003). Qué es el management. Cómo funciona y por qué nos afecta a todos. Empresa Activa, Barcelona.

Manning, N., Shepherd, G., Bum, J., y Laudares, H. (2009). Reformas de gestão pública: o que a américa latina tem a aprender com a ocde. Novos caminhos da gestão pública: olhares e dilemas. Rio de Janeiro: Qualitymark, pp. 97-148.

Mardones, R. (2008). Transantiago recargado. Revista de Ciencia Polï $\frac{1}{2}$ tica, 28(1):103-119.

Ministerio de Hacienda (2003). LEY-19882. Santiago.

Moore, M. (1998). Gestión estratégica y creación de valor en el sector público. Paidos, Barcelona.

Nickson, A. (2002). Transferencia de poítica y reforma en la gestión del sector púbico en América Latina. Revista Reforma y Democracia.

Osterwalder, A. y Pigneur, Y. (2009). Business Model Generation. Publicaciï $\frac{1}{2} \mathrm{n}$ propia, Amsterdam.
Oszlack, O. (2002). Profesionalización de la función pública en el marco de la Nueva Gestión Pública. En IV Reuinï̈; $\frac{1}{2} n$ de Ministros de la Administracï̈ $\frac{1}{2} n$ P $\ddot{z} \frac{1}{2} b l i c a$ y Reforma del Estado, Santo Domingo.

Porter, M. (1987). Ventaja competitiva. Creación y sostenimiento de un desempeño superior. Compaï $\frac{1}{2}$ ia Editorial Continental S.A., Mï $\frac{1}{2}$ xico.

Prats, J. (1999). Servicio civil y gobernabilidad democrática: Fundamentos institucionales del sistema de mérito y regímenes jurídicos y gerenciales requeridos para su eficiencia. En Losada, C., editor, $\hat{A}_{\dot{ }}$ De burócrata a gerentes? Las ciencias de la gestión aplicadas a la administración del Estado, pp. 251-289. Banco Interamericano de Desarrollo, Washington, D.C.

Ramos, C., Scrollini, F., y Solï $\frac{1}{2}$ rzano, F. (2011). El tortuoso camino hacia la profesionalización de la Alta Dirección Pública en Chile y Uruguay. Technical report, Documento de Trabajo del ICP, Montevideo.

Rehren, A. (2000). Clientelismo político, corrupción y reforma del Estado en Chile. Reforma del Estado, II:127-164.

Sotelo, A. (2012). La cadena de valor público: un principio ordenador que previene la colisión metodológica. Revista Internacional de Presupuesto Público, (80).

Tello Navarro, F. H. (2011). La política de reforma y modernización de la gestión pública en chile: Actores y procesos. Universum (Talca), 26(2):245-265.

Trefogli, G. (2013). Gestión estratégica y cración de valor en el sector público: Estudio de caso sobre el desarrollo de evaluaciones de conocimientos en el servicio civil peruano (2008-2012). Technical report, Lima.

Waissbluth, M. y Larraín, F. (2009). Modelos de gestión pública: implicancias para la planificación, evaluación y control de gestión del Estado. En Tomicic, V. y García, C., editores, Un mejor Estado para Chile. Propuesta de modernizaciï $; \frac{1}{2} n$ y reforma, pp. 541-559. Consorcio para la Reforma del Estado, Santigo. 